\title{
Artelogie
}

Recherche sur les arts, le patrimoine et la littérature de l'Amérique latine

$7 \mid 2015$

Photographie contemporaine en Amérique latine

\section{Los fotógrafos, la memoria y el 68 en México}

Alberto del Castillo Troncoso y Instituto Mora

URL: https://journals.openedition.org/artelogie/1102

DOI: 10.4000/artelogie. 1102

ISSN: 2115-6395

Editor

Association ESCAL

\section{Referencia electrónica}

Alberto del Castillo Troncoso y Instituto Mora, «Los fotógrafos, la memoria y el 68 en México»,

Artelogie [En línea], 7 | 2015, Publicado el 15 abril 2015, consultado el 11 abril 2022. URL: http:// journals.openedition.org/artelogie/1102 ; DOI: https://doi.org/10.4000/artelogie.1102

Este documento fue generado automáticamente el 11 abril 2022.

Association ESCAL 


\title{
Los fotógrafos, la memoria y el 68 en México
}

\author{
Alberto del Castillo Troncoso y Instituto Mora
}

1 La enorme importancia que ha adquirido la construcción de una memoria colectiva en algunos lugares de la América Latina durante los años recientes se desprende de la magnitud de esta represión organizada a través de distintos operativos criminales que comparten un sustrato común: la participación rectora del Estado como responsable de los crímenes contra la población civil.

2 Esta construcción memorística ha pasado por varias etapas y cambios de perfil, experimentando diversos avances y retrocesos, de acuerdo a las características de cada coyuntura, que abarcan desde dictaduras militares y estados autoritarios hasta transiciones políticas de distinto alcance hacia gobiernos democráticos. ${ }^{1}$

3 En el análisis de la revisión de este tipo de procesos la historia y la memoria desempeñan papeles importantes. Ambas se complementan, pero tienen objetivos diferentes.

4 La historia es ante todo una disciplina que aspira a la objetividad y trata de interpretar una realidad. La memoria, por su parte, intenta legitimar el pasado, trasciende el universo individual para construir una referencia colectiva y elabora relatos que posibilitan la identidad de los grupos sociales.

5 Como analizaremos en este texto, la recuperación no lineal de la memoria, con sus rupturas y continuidades ha encontrado en la fotografía y sus múltiples usos uno de sus vehículos más importantes de expresión. En los años sesenta del siglo pasado se produjeron movimientos estudiantiles a lo largo y ancho del planeta.

6 Sin embargo, sólo en México la protesta concluyó en una masacre contra la población civil en la Plaza de Las Tres Culturas el 2 de octubre de 1968 en Tlatelolco, cuando miles de soldados se enfrentaron a tiros contra un grupo de francotiradores enviados por el propio Estado. (Hobsbawm, 1994).

7 Todo ello fue documentado en su momento por algunos fotógrafos que contribuyeron con su trabajo a la creación de uno de los más importantes imaginarios políticos, que 
influyó en la reflexión política en América Latina durante las siguientes décadas. Una de las paradojas más importantes reside en el hecho de que todavía hoy, a medio siglo de distancia, conocemos muy poco sobre la visión del mundo de los creadores de este imaginario, que ocupó las páginas más importantes de la prensa a nivel nacional e internacional en la coyuntura del 68. (Del Castillo, 2012).

La combinación de los testimonios orales desplegados por los fotógrafos cuarenta años después de los sucesos y el cotejo con algunas de sus imágenes representa el núcleo central de este trabajo. Es conveniente subrayar que la lectura de testimonios orales y gráficos que analizaremos en este espacio está construída no sólo a partir de las intenciones de los fotógrafos, sino también de los usos editoriales que otros imprimieron a sus imágenes. Esta contradicción constituye la premisa básica para la interpretación de lectura de los relatos orales y las secuencias gráficas.

Cabe recordar aquí que el barrio de Tlatelolco representa uno de los espacios paradigmáticos de la memoria mexicana y latinoamericana de los últimos 10 siglos. Se trata de un importante barrio indígena, que fue el escenario de la última batalla de los mexicas en contra de los españoles a principios del siglo XVI. En ese mismo lugar coexiste una zona arqueológica prehispánica con la Iglesia virreinal de Santiago y una unidad habitacional moderna de mediados del siglo XX. Todo el lugar constituye un espacio denso, propicio como ningún otro para el ejercicio de la memoria, como lo ha mostrado el escritor mexicano Octavio Paz en diversos ensayos dedicados a la masacre y el movimiento estudiantil de 1968 ( Paz, 1970).

10 El levantamiento ciudadano de 1968 surgió a finales del mes de julio como una respuesta de los estudiantes de los dos centros de educación superior más importantes del país: el Instituto Politécnico Nacional (IPN) y la Universidad Nacional Autónoma de México (UNAM), en contra de la represión policíaca y militar del Estado.

11 En los siguientes dos meses, cientos de miles de jóvenes marcharon por las calles y reivindicaron la necesidad de un estado de derecho en un país gobernado de manera autoritaria por un régimen de partido de Estado, sin contrapesos democráticos. Fue un movimiento ágil y contestatario, que renovó las formas de protesta pública en el país y fue violentamente reprimido por el Estado la tarde del 2 de octubre, exactamente diez días antes del inicio de los XIX Juegos Olímpicos ( Álvarez Garín, 2002 ).

Como ya se señaló, un grupo importante de fotógrafos y fotorreporteros que dieron cuenta de una gesta cívica muy compleja que se desarrolló en las calles y avenidas de la ciudad de México y que adquirió una visibilidad importante en el espacio de la opinión pública nacional e internacional. ${ }^{2}$

13 En octubre de 1968 la clase política en su conjunto aplaudió el operativo gubernamental del 2 de octubre y la represión generalizada contra los estudiantes. Las cámaras de diputados y senadores apoyaron la masacre y los directores de todos los medios, incluyendo a los periódicos y las revistas expresaron su apoyo incondicional al Presidente Gustavo Díaz Ordaz y al poderoso Ministro del Interior Luis Echeverría Álvarez.

Casi medio siglo después, la presidencia de México ha exaltado el 68 como un episodio "clave" para la democracia del país y el congreso ha ordenado inscribir en "Letras de oro" el movimiento estudiantil, junto al nombre de los próceres más destacados y representativos de la nación, como Benito Juárez, Pancho Villa y Emiliano Zapata. 

sacralizadora del Estado en próceres y mártires fundadores del nuevo sistema político del país. Las coordenadas de lo "políticamente correcto" se alteraron drásticamente en unos cuantos años, incidiendo en la memoria colectiva de todos los actores sociales. hechos. Entre otros de sus objetivos está el hecho de no circunscribir el contenido del propio lugar a los acontecimientos del 2 de octubre, desarrollar una propuesta audiovisual audaz que no quedara encerrada dentro de los límites del discurso museográfico convencional y vincular al 68 mexicano con los movimientos estudiantiles producidos en el resto del planeta. ${ }^{3}$

Lo anterior implica explorar la memoria histórica desde una perspectiva amplia, que rebasa los límites de la visión política en su sentido tradicional, impulsa una perspectiva crítica que toma una distancia de posibles apologías idealizadoras, reconoce los alcances renovadores del movimiento e intenta acercarse a la lógica de los sucesos sin caer en la dinámica de las conjuras comunistas y las intrigas internacionales, pero sobre todo presenta al 68 como un proceso local inteligible y explicable por un conjunto de factores internos, que responden al control monopólico de parte del Estado y a la falta de un estado de derecho. orales y la presentación de una síntesis fotográfica compuesta por imágenes publicadas en su momento en la prensa. Este singular diálogo entre las imágenes y las palabras se complementa, pero en otras se contradice o apunta a otros ángulos, como veremos en este trabajo.

19 Todo ello conforma este lugar, el cual condensa distintas visiones en torno a los hechos, al tiempo que proporciona referencias y puntos de partida para la lectura de las nuevas generaciones, en la medida en que consideramos a la memoria no sólo como la conservación de ideas previamente retenidas, sino sobre todo, como la construcción simbólica y elaboración de sentidos del pasado.

años recientes inauguramos en este espacio una exposición, titulada "Miradas en torno al 68", la cual agregó distintos testimonios orales y fotográficos y tuvo como una de sus aportaciones conjugar entrevistas recientes a varios destacados fotógrafos de la época con las selección de algunas de sus imágenes más importantes, en su mayoría no publicadas hasta este momento.

21 En este ensayo se desarrollan algunos planteamientos sobre los usos de estos testimonios e imágenes en el contexto de esta puesta en escena museográfica. La reflexión de este trabajo retoma el concepto de "vehículos de la memoria" según el cual algunos objetos no solo representan el pasado, sino que lo incorporan y se convierten en instrumentos privilegiados en la construcción de sentido y de significados históricos. (Jelin, 2002).

22 Resulta muy significativo que este tipo de saberes y prácticas circulen y se resignifiquen en los nuevos escenarios museográficos, diseñados casi medio siglo después de los hechos.

23 Así, el análisis de la obra de estos fotógrafos es cotejado con una lectura crítica de sus testimonios orales. Con ello se proporcionan pistas sólidas para una narración de los hechos que toma distancia respecto de los puntos de vista convencionales, retoma la 
discusión sobre los distintos usos del pasado y aporta otros elementos para su comprensión e interpretación. (Traverso, 2011).

En este artículo he seleccionado 3 casos que considero muy importantes, y en algunos casos muy poco conocidos. Se trata de fotógrafos con trayectorias y un peso en la opinión pública muy distintos. Daniel Soto y Rodrigo Moya aportaron por primera vez su testimonio sobre los hechos para este trabajo, mientras que Enrique Metinides lo ha hecho en distintas ocasiones a lo largo de 4 décadas. (Morales, 2001).

La versión de los dos primeros nos permite matizar la versión oficial de los hechos, mientras que el punto de vista del segundo ha contribuido a crear un estereotipo o versión convencional de los sucesos.

Se trata de 3 marcas o referencias frente a la opinión pública elaboradas con distintos signos políticos e ideológicos. En ellas se expresa un microcosmos relevante que ilustra en torno a las distintas tendencias de la cobertura periodística, la cual contempla el linchamiento mediático y la criminalización de los estudiantes como portadores de la protesta social, pero también revela distintos indicadores de una crítica social que se fue fortaleciendo en las décadas posteriores y que replanteó la participación cívica y el cuestionamiento del poder como elementos de una necesaria transición democrática para el Estado y la sociedad mexicana de los años posteriores.

27 En este contexto deben leerse los siguientes planteamientos en torno a cada uno de estos 3 profesionales de la lente.

\section{Enrique Metinides}

A la manera del célebre fotógrafo ucraniano - neoyorkino Weegee (Arhur H. Fellig), Metinides está considerado como uno de los grandes maestros de la cobertura mediática en torno a la nota roja y el reportaje policíaco en México durante el siglo pasado. El trabajo de este autor ha sido recuperado por galerías y museos norteamericanos y europeos, que lo han convertido en los años recientes en uno de los fotógrafos mexicanos más apreciados en el extranjero.

Casi toda su vida profesional transcurrió en el diario La Prensa, un periódico de corte amarillista y sensacionalista de gran tiraje e influencia en los sectores populares de la ciudad de México. ${ }^{4}$

Dicho diario fue uno de los divulgadores más influyentes de la llamada "teoría de la conjura" argumentada por las autoridades, según la cual oscuras fuerzas de carácter comunista manipularon a los estudiantes con el objetivo de impedir la realización de los XIX olimpiada en tierra azteca. La alineación del diario con los designios y los parámetros gubernamentales se refleja en el manejo político de las notas y reportajes, así como en la estrategia editorial respecto a las fotografías publicadas de los distintos sucesos.

31 Esta línea editorial, lejos de ser casual, formaba parte de la estrategia gubernamental. Así lo demuestra la autoría disfrazada de algunos editoriales del diario por parte de importantes personajes de la clase política mexicana, como Mario Moya Palencia y su jefe, el poderoso Ministro del Interior, Luis Echeverría, quienes utilizaban la columna titulada "Granero político" para denostar a sus adversarios y poner en circulación cierto tipo de información que era leída entre líneas tanto por sus subalternos y compañeros de ruta como por sus adversarios. En el contexto de los sucesos del 68, 
dicha columna denigró y satanizó a los estudiantes y sirvió como punta de lanza para el resto de los actores políticos y sociales para que supieran a qué atenerse en relación con la línea trazada desde las oficinas de Echeverría. (Rodríguez, 2005)

En el 68, Metinides realizó la cobertura de algunos episodios relevantes del levantamiento estudiantil, que incluyeron la matanza del 2 de octubre. La mirada del fotógrafo, especializada en cuestiones criminales, encuadró con ese mismo concepto al movimiento social de los estudiantes, privilegiando la atención sobre los efectos sangrientos y nocivos de la tragedia y omitiendo las causas y razones de la violencia. Todo ello aportó un contenido justificatorio a sus imágenes, que apoyaron las consignas anticomunistas y progubernamentales predominantes en el razonamiento llevado a cabo por el periódico.

Con una amplia trayectoria profesional, Metinides ha construido a lo largo de los años un discurso testimonial convencional acerca de su participación en los hechos del 68, en la que prevalecen varios aspectos a destacar.

En principio, cabe subrayar la construcción de una retórica heroica, que focaliza la acción de los reporteros como sujetos victimizados, enfrentados a condiciones laborales en extremo adversas y a un contexto político de represión constante: "Desde que empezó el problema [Se refiere a las protestas callejeras de los estudiantes] no nos daban un día de descanso. No teníamos derecho a enfermarnos, no teníamos derecho a comer, no teníamos derecho a dormir, no teníamos derecho a nada. Y teníamos que sufrir agresiones. Todo para que no nos publicaran las fotos". (Del Castillo y González, 2008)

Por otro lado, se puede destacar también la visión del mundo de un reportero especializado en el tema policíaco, con una ausencia de reflexión en torno a las causas de la violencia y un énfasis en los resultados escandalosos de la tragedia, cuyo punto culminante se detiene en la matanza del 2 de octubre.

El testimonio esgrimido por el fotógrafo a cuatro décadas de distancia permite acercarse a estos contenidos y subrayar estas consideraciones, de acuerdo a las cuales existe una identificación de la postura del autor con el discurso generado por el Estado en aquella coyuntura. Lo significativo consiste en subrayar el hecho de que el propio Estado y la sociedad mexicana han tomado posturas distintas sobre los hechos a lo largo de estas 4 décadas, pero el testimonio del fotógrafo permanece instalado en las coordenadas políticas de la atmósfera gubernamental anticomunista, característica de un sector significativo de la sociedad mexicana y latinoamericana de los años sesenta:

Yo veo todavía reportajes en la televisión, algunos los he grabado, y he visto que iba a haber una especie de golpe de Estado contra el gobierno de México y empezaron a meter a gentes desde antes, porque yo me acuerdo que desde antes de lo del 68 hubo atentados. Me tocó inclusive ir a una casa a la colonia Condesa donde había 8 muertos despedazados cuando estaban fabricando bombas y tengo todavía una foto de un restaurante que estaba ahí en Avenida "Reforma", que le pusieron una bomba, me acuerdo de la Suprema Corte, también ahí pusieron una bomba. En el Zócalo hubo muchos atentados contra el gobierno, entonces, estoy seguro que fue otro golpe contra al gobierno, que de cierta manera lo quería frenar y acabó en la matanza del 2 de octubre. ${ }^{5}$

Por ello, resulta muy significativa la manera en que el fotógrafo vincula el movimiento estudiantil con la teoría gubernamental de la conjura comunista y el surgimiento de poderosas y misteriosas fuerzas oscuras que intentaban derrocar al Estado. 
En esta perspectiva, compartida por los sectores más conservadores, el Estado mexicano respondió con represión a los atentados terroristas orquestados en el extranjero y generados en complicidad con algunos sectores locales, ocupó militarmente los 2 centros de educación más importantes del país, el Instituto Politécnico y la UNAM en el mes de septiembre y posteriormente fue víctima de los francotiradores estudiantiles que ocasionaron la matanza del 2 de octubre en Tlatelolco. El crímen de Estado se diluye así en el testimonio oral de Metinides en el laberinto oscuro de la guerra fría.

Una secuencia de fotografías del maestro de la nota roja ilustran la portada del diario $L a$ Prensa el 25 de septiembre, el día siguiente de la ocupación militar del Instituto Politécnico, que tuvo un saldo final de varios estudiantes muertos.

En la secuencia se puede ver el operativo médico que rescata a uno de los soldados agredidos por los estudiantes. En 4 cuadros se narra la historia del hecho. El acento esta puesto en la tragedia. Sin embargo, en esta ocasión no se trata de un crimen conyugal o de un drama pasional, tan característico de la nota roja latinoamericana de la época, sino de otro hecho de violencia, cuyo origen se atribuye a la rebelión estudiantil en el pie de foto. El titular "Corrió sangre" evidencia la ausencia de cualquier otro tipo de razonamiento o explicación para describir este tipo de acontecimiento.

Una educación visual construida a lo largo de varias décadas en la prensa sensacionalista sirvió de vehículo para dotar de verosimilitud a este tipo de mensajes y contribuyó a divulgar entre sectores sociales muy amplios la visión oficial de los hechos.

Fotografía núm. 1. La Prensa, 25 de septiembre de 1968

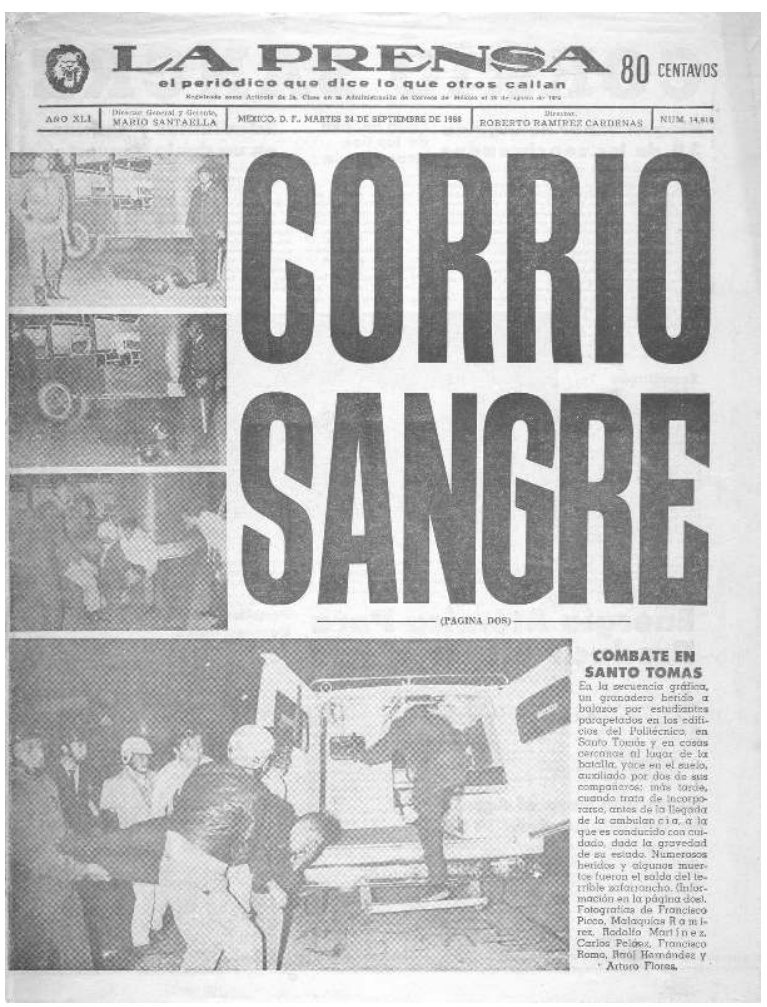

Secuencia fotográfica de Enrique Metinides. Archivo Histórico de la UNAM 
En este contexto desarrollamos una lectura de imagen acerca del manejo editorial en torno a las fotografías del autor, que nos permitirá tomar un poco de distancia y comprender el estereotipo generado por el propio Metinides, esto es, el hecho de considerar que el periódico La Prensa estigmatizó a los estudiantes a lo largo de toda la cobertura fotoperiodística de los hechos y desarrolló la misma estrategia editorial que aplicó en los casos de la nota roja, con una carga moral de corte conservador que criminalizó a los sujetos representados, en particular a las mujeres y estigmatizó sus acciones y comportamientos.

\section{Daniel Soto}

Fue el Jefe del departamento de fotografía de El Universal en 1968, uno de los periódicos fundadores de la prensa moderna en México y que en los sesentas estaba alineado a los lineamientos gubernamentales. Soto había laborado en el diario a lo largo de 20 años, por lo que pudo enfrentar con amplios recursos profesionales los distintos episodios del movimiento estudiantil y coordinar y diseñar la estrategia fotográfica con la que sus colegas y subordinados asumieron el importante reto de retratar uno de los episodios ciudadanos más relevantes de la década de los sesenta del siglo pasado en México.

Desde esta posición estratégica en el periódico, cubrió las primeras jornadas estudiantiles de la protesta en el mes de agosto y posteriormente fue testigo directo del operativo implementado algunas semanas más tarde por el gobierno para ocupar militarmente el territorio de la Ciudad Universitaria, al sur de la ciudad de México con un despliegue de 10 mil soldados y también de controlar el contenido de la cobertura fotoperiodística sobre este mismo episodio para acotarla a los lineamientos oficiales, la noche del 18 de septiembre. ${ }^{6}$

La ocupación de la Ciudad Universitaria fue justificada como una medida dolorosa, pero necesaria por la mayor parte de la prensa capitalina, aunque también fue criticada por los distintos sectores intelectuales del país. ${ }^{7}$

El testimonio que Daniel Soto expone en este artículo por primera vez después de 4 décadas de silencio resulta muy significativo, en la medida en que contradice la versión oficial del Estado mexicano acerca de la independencia de la prensa y su cobertura de los hechos y confirma que, por el contrario, la cobertura mediática del episodio se trató en realidad de un operativo de Estado escrupulosamente diseñado en la propia Presidencia de la República a través del Ministerio de Gobernación, encabezado por Luis Echeverría Álvarez, el encargado de la seguridad interna del país.

La comitiva oficial con los fotoperiodistas partió hacia el territorio universitario, de acuerdo al testimonio del fotógrafo, de las propias oficinas de Gobernación. Una vez en el campus los mandos militares organizaron un tour para los fotógrafos, que incluyó una visita guiada a las aulas con letreros y grafitis irreverentes, que supuestamente evidenciaban el vínculo de los estudiantes con la revolución cubana y ofendían e insultaban al presidente Díaz Ordaz con el epíteto de gorila, en alusión a la figura de los dictadores militares de la época.

El testimonio del fotógrafo no solo responsabiliza al Estado de la represión en el campus universitario, sino que ridiculiza la pretensión gubernamental de haber decomisado un "peligroso" arsenal de guerra al señalar que en realidad se trataba solo de algunas bombas molotov de preparación casera. 
la presencia del ejército frente al edificio emblemático de la Rectoría Universitaria. Se trata de una fotografía profesional, que se limita a ubicar 3 tanques militares y a algunos soldados en la explanada principal de la Ciudad Universitaria, esto es, presenta a los elementos castrenses en el escenario mismo de los hechos, sin adjetivarlos de manera negativa, en la medida en que la fotografía no ilustra ningún acto de represión directa en contra de los estudiantes.

Fotografía núm. 2. La ocupación militar de Ciudad Universitaria. Portada del diario "El Universal"

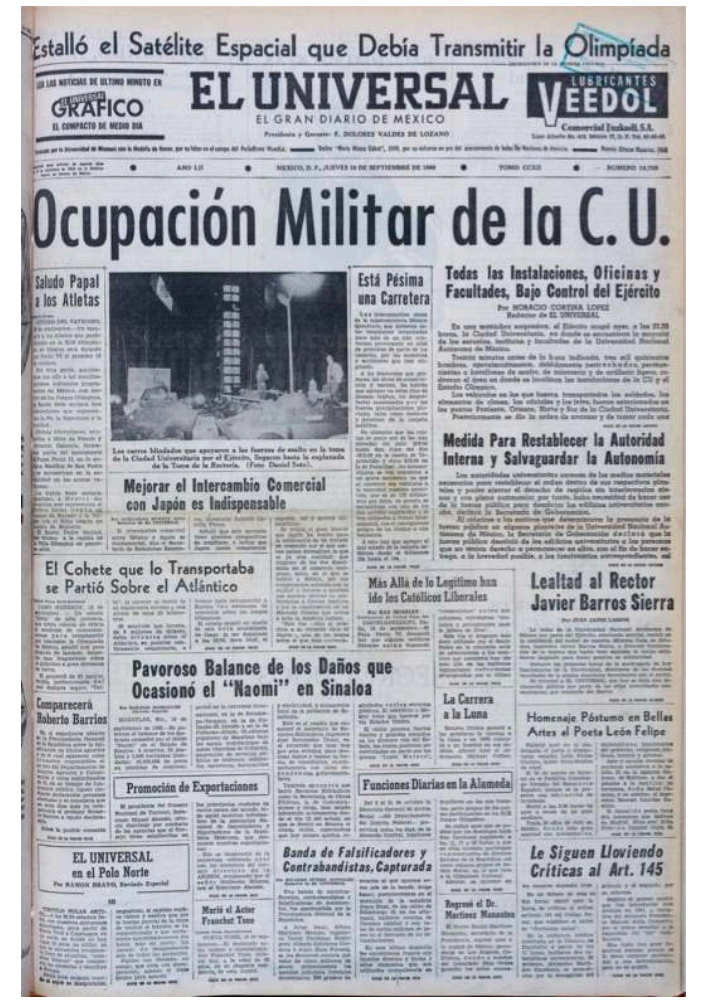

Fotografía de Daniel Soto. Archivo Histórico de la UNAM

La cobertura de El Universal, en cambio, se alineó por completo al discurso oficial y acusó a los estudiantes de preparar una intervención armada contra el gobierno. Esta cobertura sacudió y dividió como nunca antes a la opinión pública mexicana, que se debatió entre el apoyo mayoritario al gobierno y la defensa de otros sectores y de algunos connotados profesores e intelectuales en torno a la autonomía universitaria. ${ }^{8}$

La portada de El Universal incorporó una sola fotografía de Soto, en la que se mostraba

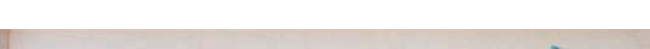

La fotografía de Soto se limita a proporcionar el contexto de la intervención. Sin embargo, el testimonio del personaje a casi medio siglo de los hechos basa su retórica en la participación del fotógrafo como sujeto. A diferencia del sujeto victimizado desarrollado por Metinides, en este caso prevalece un tono irónico, en el que el fotógrafo se enfrenta al poder sin una carga heroica y logra su propósito liberador casi por casualidad, en una atmósfera de comedia.

De esta manera, en un tono informal y coloquial, juguetón, con un alto grado de ambigüedad que le resta toda solemnidad al episodio, Soto describe su encuentro con otro fotógrafo de El Universal, en plena ocupación militar del territorio universitario. Los dos colegas se reconocen a través del cerco que los militares han formado con sus cuerpos en torno a la Ciudad Universitaria. Soto esta dentro del cerco y su colega está 
afuera, pero esto no impide una singular conversación, que termina cuando el fotógrafo finge despedirse de su amigo y le entrega el importante rollo con la película fotográfica:

[...] No nos dejaban salir. Ya eran casi las 12.30 de la noche y había que entregar el material en el periódico. Entonces, en lo que es la avenida "Insurgentes", estaba el cordón de soldados, y yo estaba tratando de salir y hablaba con los soldados, pero no me dejaban. " ¡Aquí no pasas. Tenemos órdenes de que nadie sale”, me decían. Yo les decía que era periodista y que el mismo gobierno nos había llevado a la Ciudad Universitaria en un autobus. - "Pues no, no sabemos nada de eso. Aquí no pasa nadie", me respondían. Y en eso veo a uno de los muchachos que trabajaba conmigo como fotógrafo de El Universal, que se llama Javier Rivera, quien estaba del otro lado de la valla de los militares. Yo ya había quitado mi rollo de la cámara y lo traía escondido en la mano. Le dije: "Hola, ¿Qué haces aquí?" - "Nada, quiero ver si puedo entrar al campus universitario", me respondió. "Bueno, pues, ¿Como te va?", le dije, al mismo tiempo que lo saludé con la mano, entre las cabezas de dos militares. él sintió el rollo inmediatamente en la palma de su mano y entendió lo que trataba de decirle. Entonces yo le dije: "Andale, vete rápido!", y él se fue y entregó todo el material a tiempo en el periódico. ${ }^{9}$

Una fotografía del autor que no fue publicada en el diario proyecta una realidad muy distinta y enfoca su atención en la mirada de uno de los estudiantes detenidos durante la ocupación. Con las manos en la nuca, la gestualidad y el rostro de este universitario están lejos de representar una imagen de la derrota. Por el contrario, el mensaje está más cargado hacia la proyección de un concepto de resistencia cívica. Quizá por ello el diario decidió no publicar una imagen que podría haber resultado incomoda a los lineamientos estatales y su versión de los hechos.

Para efectos de este ensayo, el contraste entre la foto publicada y la no publicada pone de relieve el peso de los editores por encima de las intenciones de los fotógrafos, al tiempo que permite descifrar un doble juego en la mirada del autor de las imágenes. 
Fotografía núm. 3. Ocupación militar de Ciudad Universitaria.

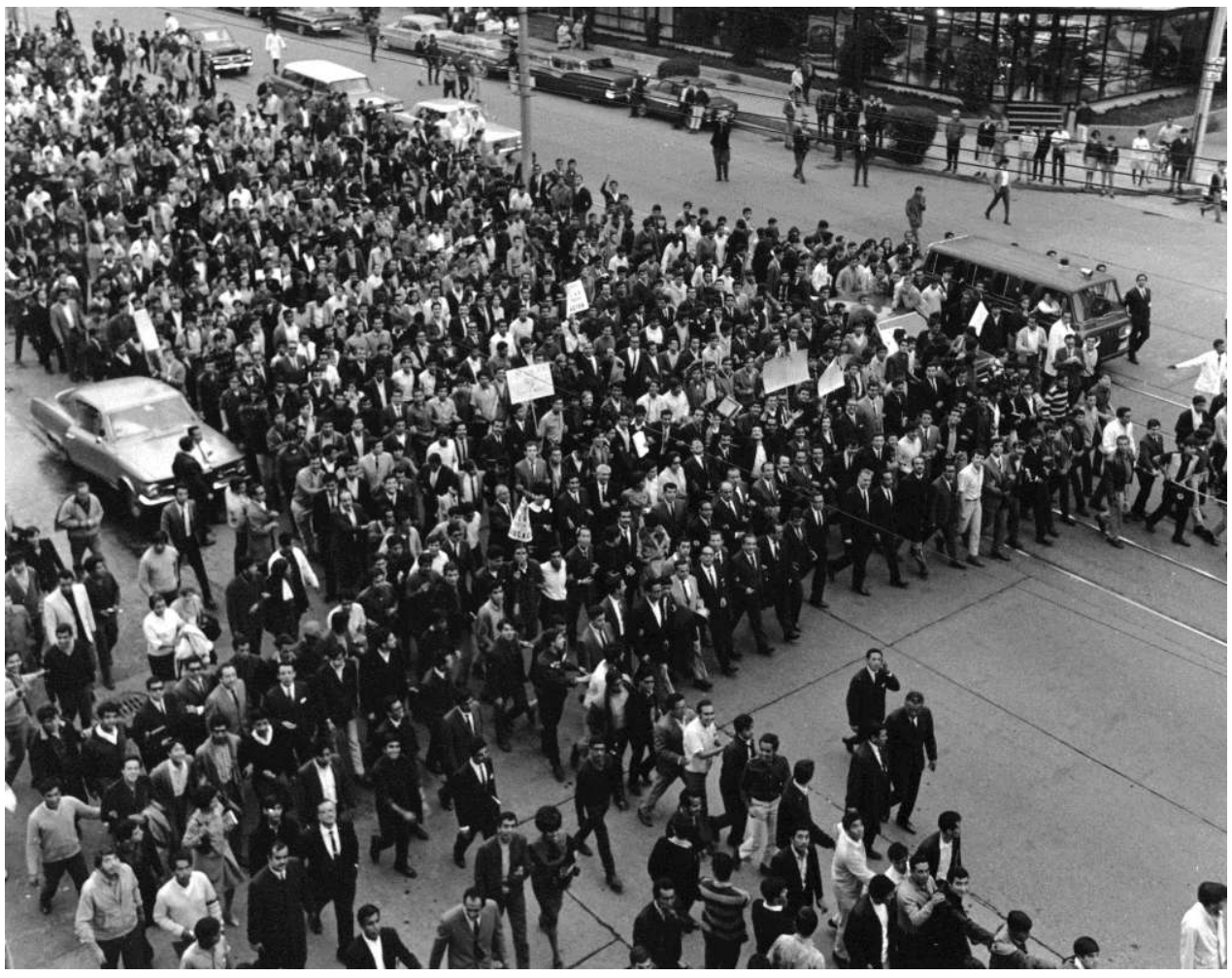

Archivo Gráfico del periódico "El Universal".

55 La noche trágica del 2 de octubre, Daniel Soto, en su calidad de jefe del Departamento de fotografía, recibió las órdenes oficiales de entregar los registros documentales de la matanza a los agentes gubernamentales, para su previsible destrucción o utilización por parte de los servicios de inteligencia del Estado.

En lugar de obedecer al gobierno y aprovechando su posición como jefe del departamento de fotografía del periódico, Soto se apresuró junto con sus colegas a esconder una parte del material, y, gracias a esto, una parte significativa de la cobertura se conservó y ha podido ser reconocida en distintas publicaciones posteriores del propio diario a lo largo de estos cincuenta años.

y apunta no tanto a la conciencia política del fotógrafo y sus colegas, cuya militancia política era inexistente, ya que no pertenecían a ningún partido, ni militaban en organización alguna, sino, sobre todo, el hecho remite a su vocación gremial y profesional de salvaguardar las imágenes como parte del registro documental de un hecho histórico que ellos sabían por su experiencia y bagaje profesional que tenía una enorme relevancia.

Se trata de una respuesta ciudadana en su sentido más amplio, la cual se rebela frente al autoritarismo del Estado en una situación límite, como lo fue el registro fotográfico de la matanza. 


\section{Rodrigo Moya}

59 La formación de Moya lo ubica como un caso muy singular en el contexto del fotoperiodismo de la época. Se trata de un fotógrafo con intereses políticos contrarios al régimen príista, con una militancia política de carácter comunista y que no participó de la cooptación tradicional de acuerdo con los usos y costumbres de aquellos años y, en cambio se vinculó a las expresiones plásticas, escenográficas y literarias más relevantes del México de finales de los cincuenta. ( Del Castillo, 2004 ).

Esta reconstrucción lo acercó de manera particular al universo del teatro, lo que lo llevó a documentar decenas de ensayos y puestas en escena dirigidas por Juan José Gurrola, Héctor Azar y Juan Ibañez, acompañados de otros personajes como el escultor Juan Soriano y el poeta Octavio Paz que contribuyeron a la transformación de los espacios de la dramaturgia mexicana y latinoamericana, con la incorporación de audaces propuestas visuales e histriónicas, que llegaron a ocupar un plano importante en el reconocimiento europeo, como lo muestra la obtención del primer lugar de la obra "Divinas Palabras" de Ramón Del Valle Inclán, bajo la dirección de Ibañez en el Festival de Teatro de Nancy en Francia en 1964 ( Del Castillo, 2012 ).

Las influencias son importantes para construir claves de referencia que nos permitan comprender el punto de vista del fotógrafo y la cultura visual que aplica a la recreación de los hechos. Así, Moya elabora su propia genealogía y traza un mapa personal y profesional que pasa por puntos cruciales para la historia del fotoperiodismo local, como es el caso de Nacho López, el fotógrafo mexicano más importante de la segunda mitad del siglo pasado, y el internacional, que se detiene en Walker Evans como prototipo de la fotografía documental norteamericana de los años treinta del siglo pasado, uno de los representantes más importantes de la historia de la fotografía documental a nivel mundial.

62 Cada fotógrafo se forma por diversas influencias, a veces locales, a veces el magisterio de algún maestro, a veces lecturas. Yo era un fotógrafo que leía de fotografía. Los libros de fotos no eran como ahora, frecuentes y abundantes; salía un libro muy de vez en cuando, y pues uno seguía a los grandes fotógrafos. Particularmente yo con las enseñanzas de Nacho López y de Guillermo Angulo y del crítico de arte Antonio Rodríguez. ${ }^{10}$

La secuencia de la marcha del Rector de la UNAM, Javier Barros Sierra, realizada el 1 de agosto de 1968 representa uno de los episodios simbólicos de mayor relevancia de todo el movimiento estudiantil de aquel año y como tal ocupa un lugar privilegiado en el archivo de Rodrigo Moya. La intervención del Rector para encabezar una marcha pacífica de protesta contra la brutalidad del ejército mexicano y la represión contra los estudiantes ocurrida en días anteriores legitimó la revuelta de los estudiantes del Instituto Politécnico y la UNAM, provocó el apoyo y la simpatía de sectores ciudadanos más amplios y consolidó el proyecto político universitario en los meses siguientes. En una palabra, dotó de racionalidad y contenido a una protesta que antes de la participación del rector era bastante limitada. ${ }^{11}$ 
Fotografía núm. 4. Marcha del Rector Barros Sierra, 1 de agosto de 1968.

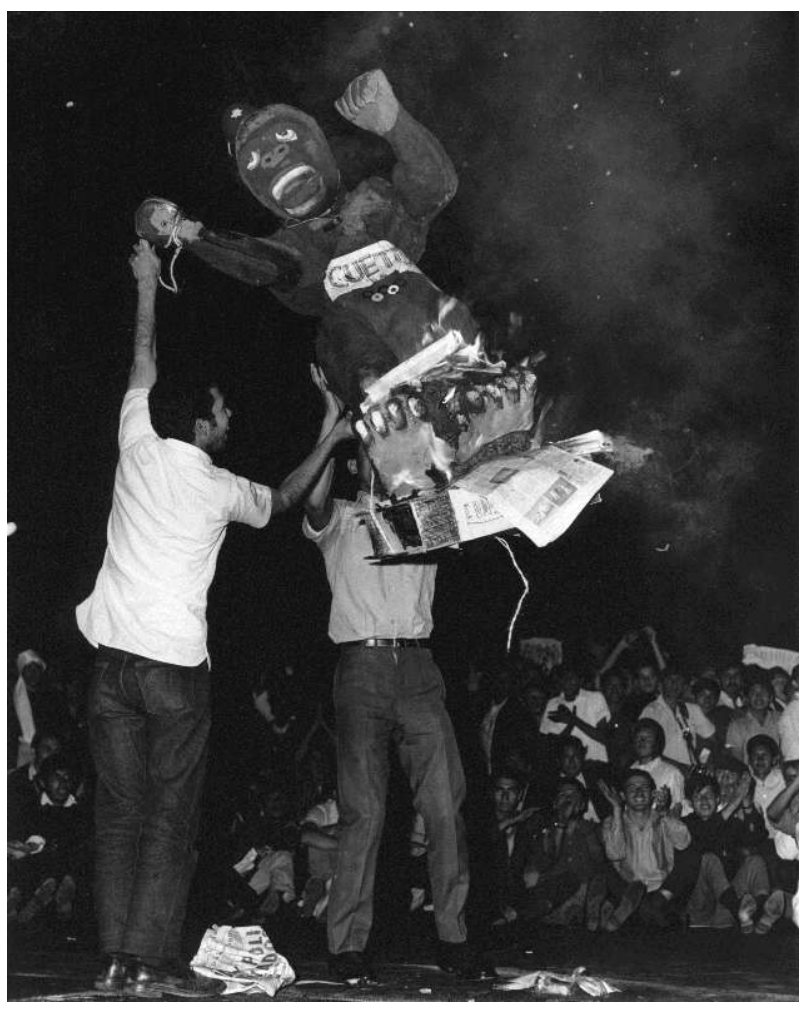

Archivo Fotográfico Rodrigo Moya

El testimonio evoca toda una lógica de trabajo del fotógrafo, en la que evidencia la voluntad crítica del registro documental y el uso de secuencias en contraposición al quehacer del fotoperiodismo convencional de aquellos años. Tambien constituye un interesante ejercicio de introspección y una reflexión sobre el propio ejercicio profesional:

Aquí me subo a un edificio y espero desde que vienen, sabiendo el movimiento, habiendo estado con ellos un kilómetro atrás. Me adelanto a paso rápido, busco siempre una azotea, pido permiso a un apartamento, me subo, tomo el ángulo alto, aquí tomo un escorzo, una diagonal, donde se ven las pancartas. Aquí vuelvo a bajar, bajo rápidamente, y entonces ya los tomo en un ángulo bajo, y voy caminando con ellos ya en medio de la lluvia. Entonces era la forma que yo siento de tomar una manifestación, meterse adentro de una manifestación y sentirla desde dentro, por varios ángulos. Es un acto de amor. Yo contengo a la manifestación, la envuelvo, pero más bien la manifestación envuelve al fotógrafo. Era un registro personal y era esta pasión que uno tenía por estos movimientos, por una actitud ideológica. Entonces uno toma parte y asistía sin ningún destinatario. Eran fotos que hasta ahora están flotando. Yo creo que es la primera vez que las fotografían juntas así. ${ }^{12}$

Se trata de toda una declaración de principios, en la que el autor reflexiona sobre su trabajo documental y llega a comparar su vínculo con la manifestación con una relación erótica y amorosa. Subjetividad y política se entretejen en estos pensamientos en los que la palabra y la imagen se nutren y complementan entre sí.

El otro momento privilegiado rescatado por el autor se refiere a la quema carnavalesca del gorila ( símbolo de la brutalidad de la represión en la América Latina de los sesenta ) que representaba al jefe de la policía de la ciudad de México, el odiado General Cueto, que pisa con sus patas la constitución política de México, la representación de la 
legalidad y el Estado de derecho, por parte de los estudiantes en el Zócalo capitalino, durante una de las marchas gigantescas llevada a cabo por los jóvenes.

De nueva cuenta, la irreverencia ciudadana frente al poder es exaltada en estas imágenes subversivas. El simbolismo salta a la vista si consideramos que el simio constituye una alegoría del poder omnímodo del presidente de la república. Se trata de uno de los e pisodios más relevantes del 68 mexicano, que desacralizó el poder a las puertas mismas del Palacio. ( Figura núm. 5 )

\section{En palabras de Octavio Paz:}

En ciertas fiestas desaparece la noción misma de orden. El caos regresa y reina la licencia. Todos e permite, desaparecen las jerarquías habituales, las distinciones sociales, los sexos, las clases, los gremios. Los hombres se disfrazan de mujeres, los señores de esclavos, los pobres de ricos. Se ridiculiza al ejército, al clero, a la magistratura. Gobiernan los niños y los locos. Se cometen profanaciones rituales, sacrilegios obligatorios. El amor se vuelve promiscuo. A veces la Fiesta se convierte en misa negra. Se violan reglamentos, hábitos costumbres [...] Así pues, la Fiesta no es solamente un exceso, es una revuelta. ${ }^{13}$

Fotografía núm. 5. La quema del gorila, 13 de agosto de 1968.

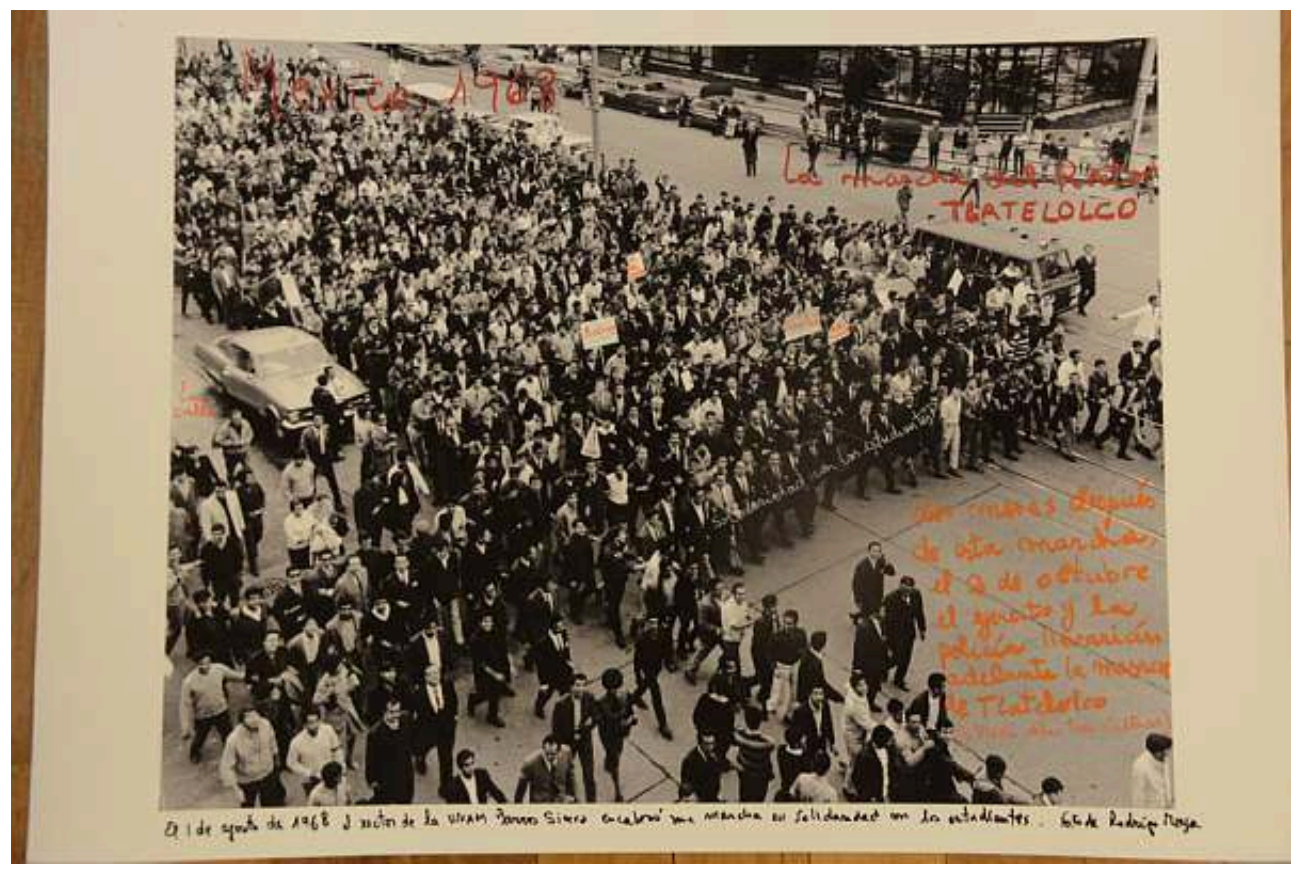

Archivo Fotográfico Rodrigo Moya el desafío ciudadano frente al poder autoritario del régimen de Estado. La primera fue representada por el líder de la máxima casa de estudios, que enarbola la bandera de la legalidad frente a la arbitraria presencia militar en los planteles universitarios y las calles del centro de la ciudad de México. La segunda ilustra la protesta festiva de los estudiantes que dramatizaron y teatralizaron los hechos políticos y pusieron en evidencia el comportamiento irracional de las autoridades, en contraposición a la legalidad racional representada por la institución universitaria.

No es casual que éstos sean los capítulos del 68 recuperados y recreados por la lente de Moya, dueño de una mirada irreverente que había desafiado al poder en otros 
importantes movimientos sociales ocurridos en México y América latina a lo largo de la década de los sesenta del siglo pasado.

71 A través de esta nueva lente es posible re-pensar el 68 como una batalla y disputa por lo símbolos entre los distintos sectores del espectro político y social y tomarlo como un eslabón que permite el dialogo con los movimientos estudiantiles de otros países. El testimonio oral del fotógrafo permite leer con mayor detalle las imágenes y contribuye a descifrar la carga simbólica de las mismas.

Al proponer por primera vez este doble testimonio oral y visual en un lapso de 4 décadas se incrementa su aportación original a la lectura e interpretación de los hechos del 68, que consiste en construir un marco de mayor pluralidad para la revisión de un acontecimiento que ocupa un lugar tan relevante en el calendario oficial de la historia reciente de México.

\section{El 68 a medio siglo de distancia}

Este tipo de trabajos contribuyen a la formación de espacios como las instalaciones museográficas, que funcionan como disparadores de la memoria colectiva. ( Fleury y Walter, 2011).

En este contexto, el tratamiento histórico del 68 ha sufrido cambios espectaculares en la realidad política mexicana: la prensa controlada del gobierno que estigmatizó a los estudiantes como alborotadores al servicio de móviles comunistas ha sido desplazada por medios con una mayor independencia del poder político y el 68 ha sido reconocido como un episodio clave para la fundación de un régimen democrático, lo cual no lo exenta de otro tipo de usos y manipulaciones políticas.

El testimonio de los distintos fotógrafos debe leerse al pie de este tipo de contradicciones y paradojas. Las escenas que ayer fueron capturadas en contextos peligrosos y con un carácter contestatario o progubernamental hoy son percibidas como parte del patrimonio documental que recrea un episodio cívico ejemplar. En ello reside uno de los puntos más relevantes del trabajo y que consiste en problematizar el vínculo de los testimonios y las imágenes para desacralizar algunos de los contenidos que han proyectado un imaginario oficial del 68 , y potenciar la apertura de una serie de matices en torno al episodio.

En ese sentido, coincidimos con Ruben Chababo, director del Museo de la Memoria de Rosario, Argentina, cuando señala que:

[...]prestar oído al murmullo inquietante que desacraliza el mito, lejos de ser descalificado bajo la acusación de estar amenazando la memoria de los derrotados de la historia, debiera ser visto como un gesto riesgoso, pero no por ello menos luminoso, de darle entidad humana -con todo lo que ello implica- a los humillados de la historia. ${ }^{14}$

El relato oral y gráfico de los profesionales de la lente aporta interesantes claroscuros para una comprensión más profunda de uno de los episodios más relevantes de la historia contemporánea latinoamericana.

Los testimonios de Daniel Soto y de Rodrigo Moya nos permiten matizar la versión oficial de los hechos, incorporando elementos con un tono irónico y crítico, mientras que el punto de vista de Enrique Metinides ha contribuido a crear un estereotipo o versión convencional de los sucesos. 
$79 \mathrm{Al}$ incorporar esta pluralidad de voces y de imágenes, el museo del 68 constituye una importante referencia para el público capitalino y se ha posicionado como uno de los lugares con documentación oral y visual sobre los hechos con mayor audiencia juvenil. La propuesta de reflexionar sobre el tema a partir de la convergencia de testimonios orales y fotografías permite no solo el enriquecimiento de la historiografía sobre un tema central para el pasado reciente de México, sino la construcción de puentes y vínculos con generaciones que no vivieron el conflicto.

En esta medida, la demanda social generada en torno al 68 mexicano en todos estos años permite revisar la perspectiva crítica del historiador como parte de un proceso cívico que acompaña la reivindicación de un importante sector de ciudadanos.

81 Este tipo de propuestas representa un punto de referencia poco utilizado en la historia del fotoperiodismo en México y América Latina. Nuestro propósito en este ensayo ha sido poner en evidencia su utilidad para el ejercicio histórico, aunque también subrayar la necesidad política de contextualizar los testimonios con otro tipo de documentos gráficos y escritos, toda vez que las imágenes y las palabras comparten una perspectiva ética construida desde la investigación. ( Huyssen, 2009).

82 La renovación creativa de este espacio o su conversión en un foro reproductor de mitos dependerán de la capacidad que se tenga para abrir el horizonte del 68 a toda una década y su flexibilidad para cotejar los hechos locales con las experiencias registradas en otras latitudes, siempre de acuerdo a las coordenadas del presente.

83 Para ello, reconocemos las diferencias entre la historia, basada en una pretensión de veracidad, y la memoria, alineada hacia un posible horizonte de fidelidad. Sin embargo, en este espacio apelamos a su necesaria interdependencia y de esa manera intentamos superar el papel simplista de una historia convencional empeñada en corregir los "errores" del recuerdo.

84 Este tipo de propuestas pone en cuestionamiento a las historias convencionales de América Latina, subordinadas a la órbita del documento escrito y poco habituadas a debatir con los espacios museográficos y abre múltiples ventanas hacia el pasado, con toda la carga subjetiva que ello implica para la construcción de una historia reciente, a través de la irrupción de procesos individuales y colectivos que se proyectan hacia el presente, esto es: "Un pasado en permanente proceso de "actualización" que, por tanto, interviene en las proyecciones a futuro elaboradas por sujetos y comunidades". ( Franco y Levin, 2007 ).

85 Por todo lo anterior resulta muy significativo reflexionar sobre la vigencia de este imaginario del 68 en relación a la memoria y puesta en escena pública respecto a crímenes posteriores en los que se ha visto inmerso en Estado mexicano.

El más reciente de todos ellos es la masacre de 43 estudiantes de la Escuela Normal de Ayotzinapa el 26 de septiembre del 2014 en el sur de México, el cual ha despertado la atención y la preocupación internacional por la participación y la colaboración de funcionarios, autoridades y policías municipales del gobierno mexicano con grupos paramilitares pertenecientes al narcotráfico, en lo que constituye un crimen de Estado. ${ }^{15}$

Una de las formas más sutiles de leer y remitirse museográficamente a los hechos del 68 y su vinculación simbólica con la masacre de Ayotzinapa ha corrido a cargo del destacado fotógrafo Marcelo Brodsky ${ }^{16}$, quien ha intervenido una de las fotografías más reconocidas de Rodrigo Moya en torno a la manifestación estudiantil del 1 de 
agosto de 1968, presentada en este ensayo ( Figura no. 4 ) y la ha relacionado con los hechos de Ayotzinapa, en el 2014, bajo el común denominador de la participación del Estado en estos crímenes de lesa humanidad. ${ }^{17}$

Para el conocido fotógrafo argentino existe una continuidad entre la revuelta estudiantil de 1968, que reivindicaba la necesidad de un Estado de derecho y las demandas de los jóvenes estudiantes de la Escuela Normal de Ayotzinapa en el sur de México, que encabezaron en el 2014 una protesta nacional contra la perversión del Estado mexicano y su transformación en un instrumento del narcotráfico y el crimen organizado, con un saldo de 80 mil muertos y 22 mil desaparecidos en los últimos 8 años. ${ }^{18}$

El trabajo de intervención de Brodsky con la fotografía de Moya ha sido incluido en la exposición de "Paris Photo", correspondiente a noviembre del 2014, lo que confirma y posiciona, la importancia del imaginario construido en torno al 68 como horizonte de referencia para ubicar este tipo de acontecimientos que sacuden a la opinión pública mexicana e internacional en relación a la participación del Estado en los crímenes contra la población civil, en uno de los lugares de mayor prestigio para la fotografía a nivel mundial, lo cual le otorga condiciones de visibilidad pública muy importantes.

Tal y como ha señalado Huyssen para el caso de Buena Memoria, la obra del fotógrafo Marcelo Brodsky, la escritura de este autor interfiere con la lectura de la imagen y dota a su contenido de una atmósfera fantasmal. La matanza de Ayotzinapa oscurece los rostros sonrientes de los estudiantes que marchan con el Rector y al mismo tiempo nos recuerda que aquella fiesta terminará en la tragedia del 2 de octubre. ${ }^{19}$

91 Nuestro propósito en este ensayo ha sido re-pensar el 68 a través de una serie de testimonios orales y visuales, que comprenden la propia dinámica de los hechos ocurridos en aquellos años, pero, dado que toda historia es pensada desde la perspectiva del presente, hemos visto de que manera este hecho se extiende hasta la actualidad, con re-lecturas e interpretaciones que posibilitan la re-significación de estas imágenes y su circulación para la configuración de una memoria colectiva.

Con esto hemos querido poner en evidencia la utilidad de este tipo de enfoques y aproximaciones para el ejercicio histórico, aunque también subrayar la necesidad política de contextualizar los testimonios con otro tipo de documentos gráficos $\mathrm{y}$ escritos, toda vez que las imágenes y las palabras comparten una perspectiva ética construida desde la investigación.

ÁLVAREZ GARÍN Raúl, La estela de Tlatelolco. Una reconstrucción histórica del movimiento estudiantil del 68, México, Itaca, 2002. BRODSKY, Nexo, Buenos Aires, La Marca/Centro Cultural Recoleta, 2001. CIFUENTES Luis, La reforma universitaria en Chile 1967-1973, Chile, Universidad de Santiago, 1997

CHABABo Rubén, Apuntes sobre el heroísmo, Santiago de Chile, Museo de la Memoria y los Derechos Humanos, 2014 Del CASTILlo Alberto, Rodrigo Moya. Una visión crítica de la modernidad, México, CONACULTA, 2006

La fotografía y el movimiento estudiantil de 1968 en México, México, Instituto Mora/Instituto de Investigaciones sobre la Universidad, 2012 

2005. 2002. 2011.

Palabra de fotógrafo. Testimonios sobre el 68, México, Instituto Mora/Centro Cultural Universitario Tlatelolco, 2013.

FRANCO Marina y LEVín Florencia,(comp.), Historia reciente. Perspectivas y desafíos para un campo de construcción, Buenos Aires, Paidós, 2007

FELD Claudia y STITES Jessica (Comp.). El pasado que miramos. Memoria e imagen ante la Historia Reciente. Buenos Aires, Paidós, 2009.

FLEURY Beatrice y WALTER Jacques ( Comps. ), Memorias de la piedra. Ensayos torno a lugares de detención y masacre, Buenos Aires, Ejercitar la memoria editores, 2011

GoNZÁLEZ Beatriz, Imágenes y representaciones del movimiento estudiantil de 1968 en el periódico La Prensa, Phd, Universidad Simón Bolivar, 2010.

HOBSBAWM Erik, Historia del siglo XX, Barcelona, Crítica, 1994.

HUYSSEN Andreas, En busca del futuro perdido. Cultura y memoria en tiempos de globalización, México, Fondo de Cultura Económica, 2002,

"El arte mnemónico de Marcelo Brodsky", en Marcelo

"Medios y memoria", in, El pasado que miramos. Memoria e Imagen ante la historia reciente, Claudia FELD y Jessica STITES MOR, Buenos Aires, Paidós, 2009

JELIN Elizabeth, Los trabajos de la memoria, Madrid, Siglo XXI, 2002

LANGLAND Victoria, "Fotografía y memoria", in, Escrituras, imágenes y escenarios ante la represión, JoLIN E. y Ana LONGONI (eds.), Madrid, Siglo XXI, 2005, p.81-105.

MARWICK Arthur, The Sixties. Cultural Revolution in Britain, France, Italy and United States, $c$. 1958-1974, Oxford, Oxford University Press, 1998.

MORALES Alfonso y ORTIZ Mauricio (eds.), Enrique Metinides. El teatro de los hechos, México, Gobierno del Distrito Federal, 2000.

MORALES Alfonso y ORTIZ Mauricio ( Eds.), Enrique Metinides : el teatro de los hechos, México, Gobierno del Distrito Federeal, 2000.

NECOECHEA Gerardo, Despues de vivir un siglo, México, Ensayos de Historia oral, INAH,

ORME William A., A culture of Collusion: An inside Look at the Mexican Press, University of Miami, North-South Center Press, 1997.

PATLAGEAN Evelyne, "La historia de lo imaginario", en Roger Chartier y Jacques Revel (coords.), Bilbao, España, La Nueva Historia, Ed. Mensajero, 1984.

PAz Octavio, El laberinto de la soledad, México, FCE, 1999, p.57

RICOEUR Paul, La memoria, la historia y el olvido, Buenos Aires, Fondo de Cultura Económica, 2000.

RICOEUR Paul, La memoria, la historia, el olvido, Madrid, Trotta, 2004.

RODRígUEZ Jacinto, La otra guerra sucia, México, Random House, 2007.

schHUdson Michael, "News, Public, Nation”, in American Historical Review, 107, 2, April,

SISMARIK Susan, Héctor García, México, Turner, 2010.

THOMSON Alistair and FReUnd Alex, Oral History and Photography, Palgrave Macmillan,

TRAVERSO Enzo, El pasado, instrucciones de uso, Buenos Aires, Prometeo, 2011. 
VOLPI Jorge, La imaginación y el poder. Una historia intelectual de 1968, México, ERA, 1998.

\section{Entrevistas}

Rodrigo MOYA, Ciudad de Cuernavaca, 10 de agosto del 2008

Enrique METINIDES (en colaboración con Beatriz González), Ciudad de México, 13 de septiembre del 2008.

Daniel sото, Ciudad de México, 29 de septiembre del 2008.

Marcelo Brodsky, Buenos Aires, 1 de diciembre del 2014.

\section{NOTAS}

1. El proceso de construcción de la memoria en la historia reciente abarca distintas formas de referirse al pasado. Para citar los dos ejemplos extremos, podemos señalar que el caso Argentina, con un ejercicio judicial que ha llevado a un grupo significativo de militares que cometieron crímenes de lesa humanidad durante la dictadura y en el caso de los estados autoritarios destaca el ejemplo de México, en el que prevalece la impunidad casi absoluta sobre estos temas, lo que resalta la importancia de la generación de nuevos testimonios que permitan nuevas lecturas sobre los hechos. ( Franco y Levin, 2007 ).

2. En el 2008 realicé, con la colaboración de Beatriz González, una serie de entrevistas con algunos de los fotógrafos del 68 mexicano: Enrique Metinides, Daniel Soto, Héctor García, Rodrigo Moya, Aarón Sánchez, María García y Enrique Bordes Mangel. El objetivo de las entrevistas integradas en un documental de divulgación muy amplia fue el de contextualizar la participación de los fotógrafos en la cobertura de los hechos. ( Del Castillo, 2012)

3. Se trata del Centro Cultural Universitario Tlatelolco de la UNAM. Por su infraestructura es un museo con una exposición permanente que da cuenta de los hechos del movimiento estudiantil de 1968 en México y su contexto. Sin embargo, tiene una condición peculiar y es que está edificado en la Plaza de las Tres Culturas, el lugar de la matanza del 2 de octubre, lo que lo acerca al perfil de sitio de memoria, ya que se exhiben distintos objetos de época.

4. El periódico La Prensa, con su director Mario Santaella, representa uno de los ejemplos más importantes del contubernio y la complicidad que caracterizaron a una buena parte de la prensa y el Estado mexicano en los años dorados del Partido Revolucionario Institucional a mediados del siglo pasado, al calor de la corrupción y la impunidad en los negocios privados y públicos ( González, 2010 ).

5. Entrevista de Enrique Metinides con Beatriz González y Alberto del Castillo, ciudad de México, 13 de septiembre del 2008.

6. Entrevista de Daniel Soto con Alberto del Castillo, ciudad de México, 29 de septiembre del 2008.

7. Entre ellos Octavio Paz, Carlos Fuentes, José Emilio Pacheco, Elena Poniatowska, Daniel Cosío Villegas y Carlos Monsivais.

8. Resulta interesante analizar la cobertura fotográfica de la ocupación militar en México y cotejarla con otros episodios semejantes ocurridos en América Latina a mediados de los sesenta, en particular con la llamada "Noche de los bastones largos" que se refiere a la ocupación castrense de la Universidad de Buenos Aires ocurrida el 29 de julio de 1966 y que ocupan un lugar importante en el espacio público sudamericano. A partir de estas imágenes puede pensarse en la creación de un gran archivo fotográfico para esta parte oscura de la historia política de 
Latinoamérica. Un archivo de esta naturaleza permitiría el diálogo entre la historia política y la cultural, toda vez que permitiría también la lectura de otros aspectos importantes de la vida cotidiana, que van de la cultura material a las gestualidades y los comportamientos.

9. Entrevista de Alberto del Castillo con Daniel Soto, ciudad de México, 29 de septiembre del 2008. 10. Entrevista de Rodrigo Moya con Alberto del Castillo, ciudad de Cuernavaca, 10 de agosto del 2008.

11. El liderazgo y el apoyo del Rector de la universidad más importante del país a la rebelión estudiantil forma parte de un caso muy particular, que no se repitió en ningún otro movimiento estudiantil del año 1968, porque en cualquier lugar del mundo la figura del Rector forma parte del establishment. En el caso de México, donde la universidad había desempeñado un papel histórico como lugar de crítica frente al autoritarismo del Estado revolucionario en la primera mitad del siglo XX, el Rector pudo apoyar a los estudiantes y convertirse en interlocutor político del gobierno. Un caso alterno se presentó en el caso de Chile, donde a partir de la reforma universitaria del 67 los rectores comenzaron a ser elegidos por votación. Ramírez (1969) y Cifuentes (1997).

12. Entrevista de Rodrigo Moya con Alberto del Castillo, ciudad de Cuernavaca, 10 de agosto del 2008.

13. Paz (1999), p. 57.

14. Chababo (2014), p. 57.

15. Los estudiantes fueron detenidos por la policía mexicana que por órdenes del Alcalde de la ciudad de Iguala en el estado de Guerrero los entregó a un grupo paramilitar conocido como los "guerreros unidos". Esto propició un paro estudiantil en toda la república mexicana, así como protestas en el resto del mundo. El estatus oficial de estos jóvenes es de "desaparecidos". La protesta mundial por estos hechos ha incluido la realización de un hecho político y artístico conocido como el "Siluetazo" por parte de civiles y estudiantes en Barcelona, que han prestado sus cuerpos para modelar y diseñar el recorte en carteles y mantas de distintas siluetas humanas que representan a los estudiantes desaparecidos. Con ello han adaptado formas y mecanismos de protesta fraguados por la sociedad civil argentina en los años de protesta contra la dictadura militar y los han aplicado al caso mexicano.

16. Marcelo Brodsky, es uno de los fotógrafos latinoamericanos más reconocidos a nivel internacional en relación al tema de los derechos humanos. Entre sus obras cabe destacar : Buena memoria (1997) y Nexo (2001).

17. En la parte superior de la fotografía Brodsky escribe con tiza roja: "43. No a un nuevo Tlatelolco". En el margen inferior de la izquierda afirma : "Los chicos estaban boteando en Iguala para poder asistir a la marcha en el DF por el aniversario de la masacre de Tlatelolco el pasado 2 de octubre del 2014".

18. Entrevista de Alberto del Castillo con Marcelo Brodsky, ciudad de Buenos Aires, 1 de diciembre del 2014.

19. "Las marcas y escrituras indicaban desapariciones, muerte y exilio. Los textos eran bastante lacónicos, reticentes, pero le añadían a los rostros adolescentes una dimensión fantasmal. Como si la foto fuera visitada por el espectro de un futuro aterrador, representable menos en imágenes que en palabras", Huyssen ( 2001), p. 9. 


\section{RESÚMENES}

La fotografía es considerada como un elemento fundamental para la elaboración de la memoria en la historia reciente de México. En este texto se analizan los testimonios orales y visuales de Enrique Metinides, Rodrigo Moya y Daniel Soto, tres destacados fotógrafos que cubrieron periodísticamente el movimiento estudiantil de 1968 en la ciudad de México. A través de su obra y de sus recorridos e itinerarios personales nos acercamos a la visión del mundo de tres creadores que contribuyeron a la formación de uno de los imaginarios visuales más poderosos de América Latina.

La photographie est considérée comme un élément clé du développement de la mémoire dans l'histoire récente du Mexique. Ce texte analyse les témoignages oraux et visuels d'Enrique Metinides, Rodrigo Moya et Daniel Soto, trois photographes de presse éminents qui ont couvert le mouvement étudiant de 1968 à Mexico. Les travaux, les voyages et les itinéraires personnels de ces trois artistes concrétisent une vision du monde qui a contribué à la formation d'un imaginaire visuel parmi les plus puissants de la photographie latino-américaine.

\section{ÍNDICE}

Mots-clés: photographie, violence, répression, démocratie, opinion publique

Palabras claves: fotografía, violencia, represión, democracia, opinión pública 